\title{
Application of red clover isoflavone extract as an adjuvant in mice
}

\author{
HONGBO CHEN ${ }^{1-3}$, XUE ZHANG $^{1}$, LONGSI LIU $^{1}$, MINGQIN CAI $^{1}$, ZHIJUN GUO $^{1}$ and LONGXIN QIU ${ }^{1-3}$ \\ ${ }^{1}$ Department of Veterinary Medicine, School of Life Sciences; ${ }^{2}$ Fujian Provincial Key Laboratory for The Prevention \\ and Control of Animal Infectious Diseases and Biotechnology; ${ }^{3}$ Key Laboratory of Preventive Veterinary Medicine \\ and Biotechnology, Longyan University, Longyan, Fujian 364012, P.R. China
}

Received August 3, 2018; Accepted October 10, 2019

DOI: $10.3892 /$ etm.2019.8315

\begin{abstract}
In the present study, the safety of red clover isoflavone extract (RCIE) and its potential adjuvant effects on the cellular and humoral immune responses to ovalbumin (OVA) were evaluated using an ICR mouse model. On day 1, the mice were first subcutaneously immunized with $100 \mu \mathrm{g}$ OVA, $100 \mu \mathrm{g}$ OVA $+200 \mu \mathrm{g}$ aluminum hydroxide gel (alum) or OVA + 50, 100 or $200 \mu \mathrm{g}$ RCIE (RCIE + OVA), following which booster immunization was performed on day 15 . After 2 weeks, the stimulation of splenocyte proliferation and levels of serum antibodies were measured. No notable stress responses were observed after the initial and booster immunization. Splenocyte proliferation was significantly increased in mice immunized with OVA + $100 \mu \mathrm{g}$ RCIE $(\mathrm{P}<0.01)$. The levels of $\mathrm{IgG}, \operatorname{IgG} 1$ and $\operatorname{IgG} 2 \mathrm{a}$ antibodies in serum were also significantly increased in OVA + RCIE groups compared with the OVA control group $(\mathrm{P}<0.05)$. In the OVA + RCIE groups, serum levels of interleukin (IL)- 2 , interferon- $\gamma$ (IFN- $\gamma$ ) and IL-10 were increased, and the mRNA expression levels of IL-2, IFN- $\gamma$, IL-4, IL-10, T-bet and GATA-3 were also significantly increased compared with the OVA control group $(\mathrm{P}<0.05)$ in splenocytes. In addition, as an adjuvant, RCIE significantly increased the survival rates of mice inoculated with an $E$. coli vaccine and enhanced the early immune protection against pathogenic $E$. coli. In conclusion, these findings suggest that RCIE can be used as a safe vaccine adjuvant and supports its use in clinical applications.
\end{abstract}

\section{Introduction}

Technological advancements in genetic engineering and antigen purification technology have accelerated the production of subunit antigens and peptides in recent years. These antigens confer many advantages over traditional vaccines,

Correspondence to: Professor Longxin Qiu, Department of Veterinary Medicine, School of Life Sciences, Longyan University, 1 Dongxiao North Road, Longyan, Fujian 364012, P.R. China

E-mail: qlongxin@tom.com

Key words: red clover isoflavone extract, ovalbumin, adjuvants, antibody including smaller molecular weight, higher purity and generally improved safety $(1,2)$; however, following purification, they exhibit lower reactivity and immunogenic potential compared with conventional vaccines, especially when derived from recombinant proteins and DNA (3). Therefore, there is an urgent need to develop novel vaccination adjuvants to improve antigen immunogenicity. Although various adjuvants have been used in conjunction with experimental vaccines, most display harmful effects, including poor immune efficacy and safety problems, which limit their potential for use in vaccines $(4,5)$.

Adjuvants have profound effects on the immune response, which can skew the immune system toward either $\mathrm{T}$ helper (Th)1- or Th2-type responses (6-8). Elevated levels of the cytokines interleukin (IL)- 2 , tumor necrosis factor- $\beta$ (TNF- $\beta$ ) and interferon- $\gamma($ IFN- $\gamma)$, coupled with the enhanced production of immunoglobulin ( $\operatorname{IgG}) 2 \mathrm{a}, \operatorname{IgG} 2 \mathrm{~b}$ and $\mathrm{IgG} 3$, are characteristics of the Th1 immune response in mice (9). By contrast, the Th2 response is characterized by elevated levels of the cytokines IL-4, IL-5 and IL-10, alongside enhanced production of IgG1 and secretory IgA (10). The adjuvants that are currently used predominantly stimulate the Th2 rather than the Th1 immune responses. For instance, lipid A and its derivatives do not stimulate cytotoxic T lymphocytes (CTLs) in animals immunized with antigens, whilst water/oil emulsion adjuvants and aluminum hydroxide gel (alum) adjuvants can only elicit Th2-based immunity (11). It is of great interest to improve the efficacy of adjuvants in activating both the Th1 and Th2 responses as well as the safety.

In general, extracts from traditional Chinese medicine enhance immune responses and do not exhibit toxicity to normal, healthy cells, making them attractive candidates as vaccine adjuvants (12). Over the past decade, research on immune adjuvants has focused mainly on polysaccharides and saponins $(12,13)$. However, they have disadvantages, including lack of activity, toxicity, hemolysis and the potential to cause infection $(4,5)$.

Isoflavones have been previously demonstrated to exhibit a number of effects on the immune function of animals, characterized by enhancement of the immune response and the regulation of excessive inflammatory cytokine expression (14). Rasouli and Jahanian (15) demonstrated that the isoflavone genistein not only increased the weight and growth of broiler chicks, but also exerted beneficial effects on the immunological response and increased the proportion of lymphocytes 
to heterophils. In addition, isoflavones significantly improved serum antibody levels against swine fever and enhance the reactivity of $\mathrm{T}$ lymphocytes to phytohemagglutinin (16). Importantly, a previous study found that diet supplementation with red clover isoflavone extract (RCIE) significantly increased the levels of antibodies in the serum of piglets, eased the inhibition of piglet growth induced by immune stress, and significantly decreased the secretion and expression of inflammatory cytokines including TNF- $\gamma$ and IL-6 (17). The aforementioned studies suggest that RCIE has immunoregulatory properties, highlighting its promise as a potential vaccine adjuvant. Although previous studies of RCIE have focused on its ability to improve immune function in humans (18), the possible use of RCIE as an immune adjuvant has not been previously reported. Therefore, in the present study, the role of RCIE as possible vaccine adjuvant was explored.

\section{Materials and methods}

Materials. Ovalbumin (OVA), concanavalin A (ConA) and lipopolysaccharide (LPS) were purchased from Sigma-Aldrich (Merck KGaA). Goat anti-mouse IgG (cat. no. 1036-05), IgG1 (cat. no. 1070-05) and IgG2a (cat. no. 1080-05) horseradish peroxidase conjugates were purchased from SouthernBiotech. The RPMI-1640 medium was purchased from Hyclone (GE Healthcare Life Sciences). Fetal bovine serum (FBS) was supplied by Hangzhou Sijiqing Biological Engineering Materials Co., Ltd. Aluminum hydroxide gel (alum) was supplied by Zhejiang Wanma Pharmaceutical Co., Ltd. Cell Counting kit-8 (CCK-8) was purchased from Vazyme. All other chemicals were of analytical reagent grade. The ELISA kits (IFN- $\gamma$, cat. no. F10660; TNF- $\alpha$ cat. no. F11630; IL-2 cat. no. F10780; IL-4 cat. no. F10810; and IL-5 cat. no. F10820) were from Shanghai Westang Biotechnology Co., Ltd. FITC/phycoerythrin (PE) rat anti-mouse CD4/CD8 antibodies (cat. no. FMD001-050) were purchased from Beijing 4A Biotech Co., Ltd. RNAiso plus ${ }^{\circledR}$ (cat. no. 9108), First Strand cDNA Synthesis kit (cat. no. RR036A) and SYBR ${ }^{\circledR}$ Premix Ex Taq ${ }^{\mathrm{TM}}$ were purchased from Takara Biotechnology Co., Ltd. Pathogenic porcine Escherichia coli (E. coli) (19) was kindly provided by Dr Jingxuan Ni (Longyan University). RCIE (cat. no. NAT-177) was purchased from Naturalin Bio-Resources Co., Ltd and standardized to obtain a concentration of $10 \%$ isoflavone (consisting of $10.2 \%$ formononetin, $9.6 \%$ biochanin A, $0.32 \%$ genistein and $0.08 \%$ daidzein). The solubility of RCIE was improved by treating with $\mathrm{NaOH}$ at $\mathrm{pH}$ 12 and $60^{\circ} \mathrm{C}$ for $6 \mathrm{~h}$ as previously reported $(20,21)$.

Animal experiments. A total of 100 female ICR (CD-1) mice (age, 6 weeks, grade II; weight range, 18-22 g) were purchased from Shanghai SLAC Laboratory Animal Co., Ltd. (certificate no. SCXK2016-0003). All mice were maintained under the conventional housing conditions for one week prior to experiments. They were housed under controlled conditions, specifically at $24 \pm 2^{\circ} \mathrm{C}$, with $50 \pm 10 \%$, humidity with a $12 \mathrm{~h}$ light/dark cycle, and were provided free access to food and drinking water.

Induction of the immune response following OVA immunization with adjuvants. The experimental protocol for testing the immune adjuvant response induced by RCIE combined with OVA was as described in previous studies $(3,22)$. Briefly, the mice were divided into 6 groups ( $n=10$ mice/group): Saline group was defined as blank control; other groups of mice were subcutaneously immunized with $100 \mu \mathrm{g}$ OVA alone or $100 \mu \mathrm{g}$ OVA + adjuvant (200 $\mu \mathrm{g}$ alum or 50,100 or $200 \mu \mathrm{g}$ RCIE) on day 1. Mice received a booster injection after 2 weeks. Splenocytes, serum and peripheral blood were collected 2 weeks following the booster injection. After immunization, the mental state (23), diet and activity of the mice was monitored every day.

Vaccine challenge using $E$. coli with adjuvants. A challenge test using RCIE combined with $E$. coli vaccine was conducted in mice as previously described $(19,21)$. Pathogenic E. coli was inactivated using $0.2 \%$ formaldehyde at $65^{\circ} \mathrm{C}$ for $8 \mathrm{~h}$. Following a sterility test, the live $E$. coli vaccine was prepared to a final concentration of $1 \times 10^{8} \mathrm{CFU} / \mathrm{ml}$.

A total of 40 mice were randomly divided into the following four groups ( $n=10 /$ group): i) Vehicle group, which was subcutaneously injected with $0.2 \mathrm{ml}$ saline; ii) saline $+E$ coli group, which was subcutaneously injected with $0.1 \mathrm{ml} \mathrm{E}$. coli vaccine (containing $1 \times 10^{7} \mathrm{CFU}$ ) and $0.1 \mathrm{ml}$ saline; iii) alum $+E$. coli group, which was subcutaneously injected with $0.1 \mathrm{ml} \mathrm{E}$. coli vaccine (containing $1 \times 10^{7} \mathrm{CFU}$ ) and $0.1 \mathrm{ml}$ alum $(200 \mu \mathrm{g} / 0.1 \mathrm{ml})$; and iv) RCIE $+E$. coli group, which was subcutaneously injected with $0.1 \mathrm{ml} E$. coli vaccine (containing $1 \times 10^{7} \mathrm{CFU}$ ) and $\left.0.1 \mathrm{ml} \mathrm{RCIE} \mathrm{(100} \mu \mathrm{g} / 0.1 \mathrm{ml}\right)$. Each mouse was subsequently injected with $0.2 \mathrm{ml}\left(2 \times 10^{7} \mathrm{CFU}\right)$ pathogenic $E$. coli 3 days following immunization. Mouse mortality was recorded $2 \mathrm{~h}$ following bacterial challenge, and every $6 \mathrm{~h}$ thereafter. The survival rate (\%) was calculated as follows: (The number of surviving mice/total number of mice) $\mathrm{x} 100$.

Humane and experimental endpoints. For the present study, humane endpoints were established and applied at the earliest experimental timepoint without adversely affecting scientific objectives. The endpoints for the animal experiments were 2 weeks following the booster injection and $48 \mathrm{~h}$ after challenge with pathogenic $E$. coli bacteria, following which all animals were humanely euthanized. Firstly, each mouse was anesthetized with $2-5 \%$ isoflurane by inhalation and anesthesia was subsequently confirmed by blink reflex examination. Blood samples were then extracted by orbital sinus puncture following anesthesia, after which the mice were sacrificed by cervical dislocation. To minimize animal suffering, the experimental design was optimized such that alternatives were considered, pain and the number of animals used were kept to a minimum, and only qualified personnel were permitted to perform the experiments. All experiments were performed in accordance with the guidelines of the Animal Ethics Committee of Fujian province (Fujian, China) and were approved by the Institutional Animal Care and Use Committee of Longyan University (Longyan, China).

Splenocyte proliferation assay. Splenic tissues were collected from the mice under sterile conditions. The spleens were transferred to a 200-mesh cell strainer and ground to obtain cell suspensions in PBS. Following erythrocyte lysis, the 
splenocytes were cultured in RPMI-1640 medium supplemented with $10 \% \mathrm{FBS}$ in an incubator with $37^{\circ} \mathrm{C}$ and $5 \% \mathrm{CO}_{2}$. Next, the splenocytes (100 $\mu \mathrm{l} /$ well) were seeded into 96-well plates at a density of $1 \times 10^{7}$ cell/ml before ConA $(5 \mu \mathrm{g} / \mathrm{ml})$, LPS $(5 \mu \mathrm{g} / \mathrm{ml})$, OVA $(10 \mu \mathrm{g} / \mathrm{ml})$ or media were added to the wells to a final volume of $200 \mu \mathrm{l}$. After $72 \mathrm{~h}$ incubation, cell viability was measured using the CCK- 8 assay, according to the manufacturer's protocols. The stimulation index (SI) was calculated using the following formula: $\mathrm{SI}=$ absorbance value at OD $450 \mathrm{~nm}$ for mitogen-activated cultures/absorbance value for non-stimulated cultures.

Measurement of OVA-specific antibodies. The levels of OVA-specific IgG, IgG1 and $\operatorname{IgG} 2$ a antibodies in mouse serum were measured using an indirect ELISA method as previously described (5). Briefly, microtiter plate wells were first coated with $100 \mu$ l OVA solution $(50 \mu \mathrm{g} / \mathrm{ml}$ dissolved in $50 \mathrm{mM}$ carbonate-bicarbonate buffer, $\mathrm{pH} \mathrm{9.6)} \mathrm{for} 24 \mathrm{~h}$ at $4^{\circ} \mathrm{C}$. The wells were then washed three times with PBS containing $0.05 \%$ Tween-20 and then blocked with 5\% bovine serum albumin (cat. no. ST023; Beyotime Institute of Biotechnology) at $37^{\circ} \mathrm{C}$ for $2 \mathrm{~h}$. The serum was diluted $1: 10$ with $0.5 \% \mathrm{BSA} / \mathrm{PBS}$. Following a further three washing steps, $100 \mu \mathrm{l}$ diluted serum sample or $0.5 \% \mathrm{BSA} / \mathrm{PBS}$ (control) was added (in triplicate) to the wells and incubated for $2 \mathrm{~h}$ at $37^{\circ} \mathrm{C}$. Next, after three washing steps, $100 \mu 1$ horseradish peroxidase (HRP)-conjugated antibody (IgG, 1:10,000; IgG1, 1:4,000; IgG2a, 1:4,000) or $0.5 \%$ BSA/PBS (control) was added to each well. The plates were further incubated for $1 \mathrm{~h}$ at $37^{\circ} \mathrm{C}$. After washing, the wells were incubated with TMB chromogenic substrate in $37^{\circ} \mathrm{C}$ for $30 \mathrm{~min}$. The substrate reaction was stopped by the addition of $50 \mu \mathrm{l}$ of $2 \mathrm{M}$ sulfuric acid. The absorbance value at $490 \mathrm{~nm}$ was measured for each well using a microplate reader.

Serum cytokine measurements by ELISA. Serum levels of IL-2, IFN- $\gamma$, TNF- $\alpha$, IL- 4 and IL-5 were quantified using commercial ELISA kits according to the manufacturers' protocols.

Flow cytometry. Blood was collected from the mice by retroorbital exsanguination into tubes containing the anticoagulant heparin. The number of peripheral blood cells in serum isolated from the mice immunized with OVA was detected using flow cytometry. A total of $10 \mu \mathrm{l}$ FITC-conjugated CD4 $(0.25 \mu \mathrm{g})$ and $5 \mu \mathrm{l}$ PE-conjugated CD8 $(0.25 \mu \mathrm{g})$ monoclonal antibodies were added to $50 \mu 1$ anticoagulant blood. This mixture was mixed and incubated gently at room temperature for $30 \mathrm{~min}$ in the dark. $1.8 \mathrm{ml}$ hemolysin solution was added to each tube, and incubated at $37^{\circ} \mathrm{C}$ for $10 \mathrm{~min}$. Following centrifugation at $1,500 \mathrm{x}$ g, the pelleted cells were rinsed using fluorescence-activated cell sorting (FACS) buffer (2\% FBS in PBS) before resuspension in $0.5 \mathrm{ml}$ FACS buffer. FACS data acquisition was performed on the BD FACS Calibur ${ }^{\mathrm{TM}}$ system (BD Biosciences), and the data was analyzed on Novo express 1.3 software (ACEA Biosciences, Inc.).

Reverse transcription-quantitative PCR (RT-qPCR) for cytokine gene expression. Splenocytes were seeded $\left(5 \times 10^{6}\right.$ cells $/ \mathrm{ml}, 1 \mu \mathrm{l} /$ well $)$ into 24 -well plates, and ConA $(5 \mu \mathrm{g} / \mathrm{ml})$ was then immediately added. After $12 \mathrm{~h}$ treatment, cells were harvested and total RNA was extracted using TRIzol ${ }^{\circledR}$ according to the manufacturer's protocol. The RNA was reverse-transcribed to cDNA using a First Strand cDNA Synthesis kit according to the manufacturer's protocol. The cDNA samples were stored at $-20^{\circ} \mathrm{C}$ until further use. qPCR was subsequently performed in a $20 \mu$ l total reaction volume consisting of $2 \mathrm{X} \mathrm{SYBR}{ }^{\circledR}$ Premix Ex Taq ${ }^{\mathrm{TM}}(10 \mu \mathrm{l}), 0.5 \mu \mathrm{l}$ each

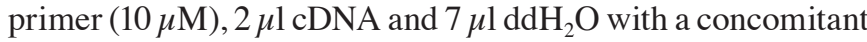
reaction condition $\left(10 \mathrm{~min}\right.$ at $95^{\circ} \mathrm{C}$, then followed by 35 cycles of $30 \mathrm{sec}$ at $94^{\circ} \mathrm{C}, 30 \mathrm{sec}$ at $55^{\circ} \mathrm{C}$ and $60 \mathrm{sec}$ at $72^{\circ} \mathrm{C}$ ). The sequences of the primers used are shown in Table I. Relative expression levels of mRNAs using $\beta$-actin as an internal control were analyzed using the $2^{-\Delta \Delta \mathrm{Cq}}$ method (24).

Statistical analysis. Values are expressed as the mean \pm SEM. Differences between the experimental and control groups were analyzed using SPSS 20.0 software (IBM Corp.). One-way ANOVA followed by Student-Newman-Keuls multiple comparison test was used for multigroup analyses. Survival rates were analyzed using the log-rank test in GraphPad Prism software (version 6; GraphPad Software, Inc.). $\mathrm{P}<0.05$ was considered to indicate a statistically significant difference.

\section{Results}

Clinical observations. No notable stress responses, including visible changes in daily appetite, mental state or motor ability were observed in the mice following the first immunization and booster immunization 2 weeks later. In addition, no differences in body weight were observed after immunization between the adjuvant groups (OVA + RCIE, OVA + alum) and control groups (saline and OVA alone) (data not shown).

Effect of OVA/RCIE immunization on splenocyte proliferation. The effects of RCIE-OVA immunization on splenocyte proliferation in mice are shown in Fig. 1. Splenocyte viability in the OVA + RCIE (50 or $100 \mu \mathrm{g}$ ) and OVA + alum groups was significantly higher compared with that of the OVA control group following OVA stimulation $(\mathrm{P}<0.05$ or $\mathrm{P}<0.01)$. Splenocytes isolated from mice immunized with OVA + RCIE (100 and $200 \mu \mathrm{g}$ ) exhibited significantly higher cell viability following treatment with LPS compared with those from mice immunized with OVA alone $(\mathrm{P}<0.05)$. Splenocytes isolated from OVA + RCIE $(100 \mu \mathrm{g})$ - and OVA + alum-immunized mice stimulated with ConA displayed significantly increased cell viability compared with those from the OVA control group $(\mathrm{P}<0.05)$. However, no significant differences were observed between the OVA and OVA + RCIE (50 or $200 \mu \mathrm{g}$ ) groups following ConA stimulation. The results demonstrated the effect of RCIE on improving the cellular immune response.

Effect of OVA/RCIE immunization on the serum antibody response. The levels of OVA-specific IgG, IgG1 and IgG2a antibodies are shown in Fig. 2. Serum IgG levels were significantly higher in the OVA + alum and OVA + RCIE $(50,100$ and $200 \mu \mathrm{g})$ groups compared with the OVA group $(\mathrm{P}<0.05$ or $\mathrm{P}<0.01$ ). In addition, serum IgG1 levels were significantly higher in all RCIE-immunized groups of mice compared with the OVA group. No significant differences were observed in the total serum IgG1 levels between the OVA + alum group 
Table I. Sequences of primers used for PCR.

\begin{tabular}{ll}
\hline Gene & \multicolumn{1}{c}{ Primer sequence } \\
\hline$\beta$-actin & 5'-AGCGGTTCCGATGCCCT-3' \\
& 5'-AGAGGTCTTTCGGACGGATGTCAACG-3' \\
IL-2 & 5'-GCACCCACTTCAAGCTCCA-3' \\
& 5'-AAATTTGAAGGTGAGCATCCTG-3' \\
IFN- $\gamma$ & 5'-GCTTTGCAGCTCTTCCTCATG-3' \\
& 5'-CTTCCACATCTATGCCACTTGAG-3' \\
IL-4 & 5'-GAGACTCTTTCGGGCTTTTCG-3' \\
& 5'-CAGGAAGTCTTTCAGTGATGTGG-3' \\
IL-10 & 5'-CCAGTTTTACCTGGTAGAAGTGATG-3' \\
& 5'-CTTGCTCTTATTTTCACAGGGGAG-3' \\
T-bet & 5'-ATTGCCCGCGGGGTTG-3' \\
& 5'-GACAGGAATGGGAACATTCGC-3' \\
GATA-3 & 5'-GGTCAAGGCAACCACGTC-3' \\
& 5'-CATCCAGCCAGGGCAGAG-3'
\end{tabular}

IL, interleukin; IFN- $\gamma$, interferon- $\gamma$; TNF- $\alpha$; tumor necrosis factor- $\alpha$.

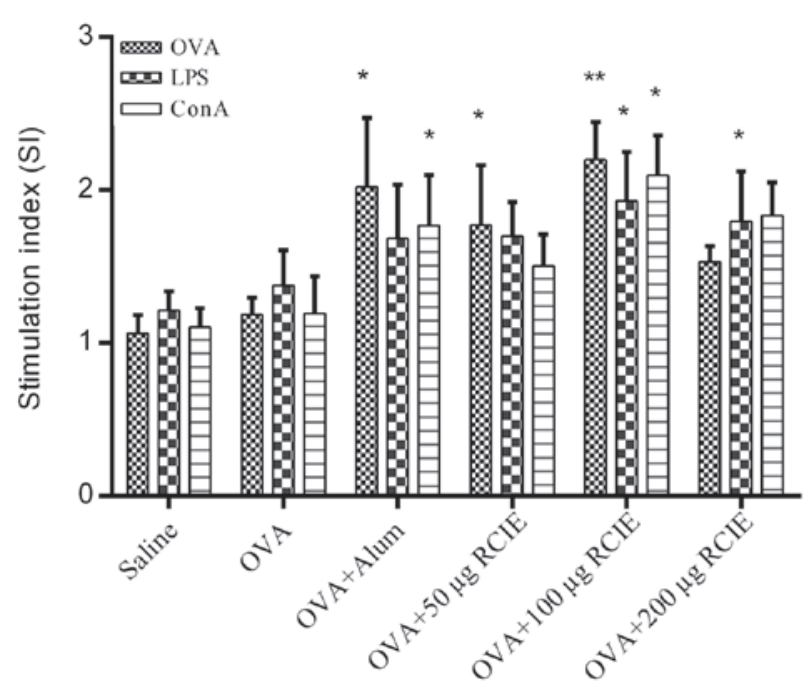

Figure 1. Effect of OVA, LPS or ConA stimulation on the cell viability of splenocytes isolated from mice immunized with OVA only, OVA + RCIE or OVA + alum. Values are presented as mean $\pm \operatorname{SEM}(n=10) .{ }^{*} \mathrm{P}<0.05$ and ${ }^{* * *} \mathrm{P}<0.01$ vs. OVA. OVA, ovalbumin; LPS, lipopolysaccharide; ConA, concanavalin A; alum, aluminum hydroxide gel; RCIE, red clover isoflavone extract.

and the mouse groups immunized with OVA + RCIE. RCIE $(50 \mu \mathrm{g})$ and RCIE (100 and $200 \mu \mathrm{g})$ also significantly increased total serum IgG2a levels in OVA-immunized mice $(\mathrm{P}<0.05$ or $\mathrm{P}<0.01$, respectively), but no significant differences in serum $\operatorname{IgG} 2 \mathrm{a}$ levels were identified between the OVA + alum and OVA alone groups. Therefore, these observations suggest that alum only significantly enhanced the levels of Th2-type antibodies, whereas the levels of Th1-type antibodies were significantly increased by RCIE compared with alum at appropriate levels.

Levels of cytokines in OVA-immunized mice. The levels of the cytokines IFN- $\gamma$, TNF- $\alpha$, IL-2, IL-4 and IL-5 were next

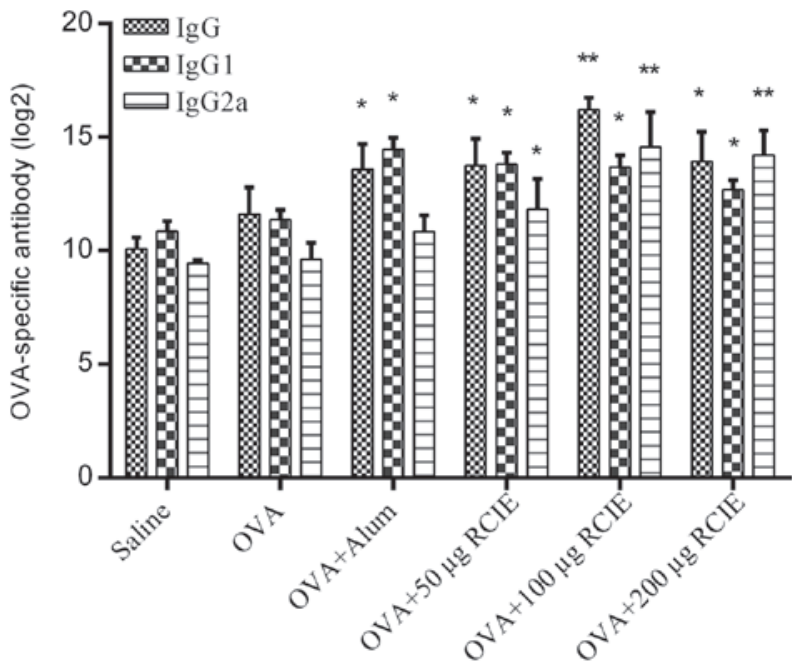

Figure 2. Effect of RCIE or alum adjuvant on the serum levels of OVA-specific $\mathrm{IgG}, \mathrm{IgG} 1$ and IgG2a antibodies in OVA-immunized mice. Values are presented as mean \pm SEM $(n=10)$. ${ }^{*} \mathrm{P}<0.05$ and ${ }^{* *} \mathrm{P}<0.01$ vs. OVA. OVA, ovalbumin; alum, aluminum hydroxide gel; RCIE, red clover isoflavone extract; IgG, immunoglobulin G.

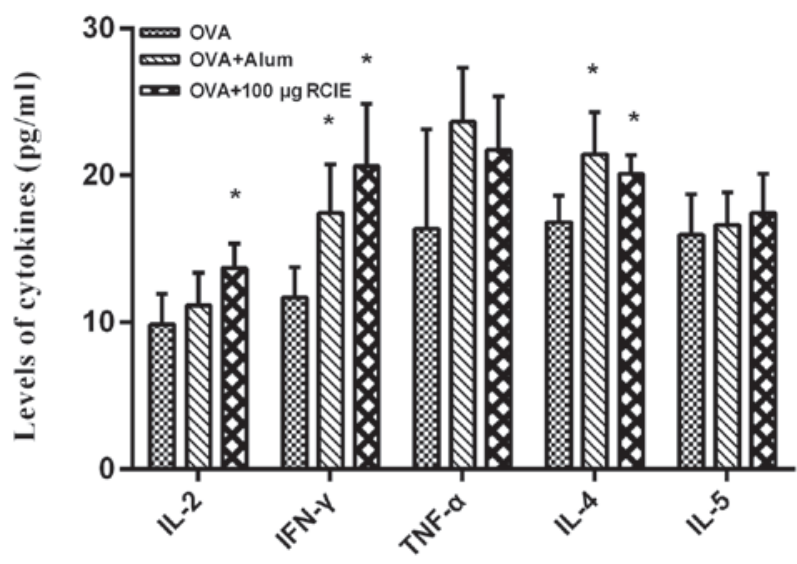

Figure 3. Effect of RCIE or alum adjuvant on the serum levels of Th1 or Th2 cytokines in OVA-immunized mice. Values are presented as mean \pm SEM $(\mathrm{n}=10) .{ }^{*} \mathrm{P}<0.05$ vs. OVA. IL, interleukin; IFN- $\gamma$, interferon- $\gamma$; TNF- $\alpha$; tumor necrosis factor- $\alpha$; OVA, ovalbumin; alum, aluminum hydroxide gel; RCIE, red clover isoflavone extract; $\mathrm{Th}, \mathrm{T}$ helper.

measured using ELISA kits and the results are shown in Fig. 3. The serum levels of IFN- $\gamma$, IL-2 and IL-4 in mice immunized with OVA + RCIE $(100 \mu \mathrm{g})$ were significantly higher compared with those in the OVA group $(\mathrm{P}<0.05)$. Although increases were observed in the levels of TNF- $\alpha$ and IL- 5 in the OVA + RCIE group compared with the OVA group, no statistically significant differences were detected. This suggests that RCIE can significantly enhance the levels of Th1 and Th2 cytokines in OVA-immunized mice.

Effect of RCIE on T-lymphocyte subsets in peripheral blood. The effects of RCIE on the levels of $\mathrm{CD}^{+}$and $\mathrm{CD} 8^{+} \mathrm{T}$ cells in the blood from OVA-immunized mice are summarized in Fig. 4. Compared with the OVA group, the proportion of $\mathrm{CD} 4^{+}$ $\mathrm{T}$ cells in mice immunized with OVA + RCIE $(100 \mu \mathrm{g})$ was significantly increased $(\mathrm{P}<0.05)$. No significant differences were detected in the proportion of $\mathrm{CD} 4^{+} \mathrm{T}$ cells between the 

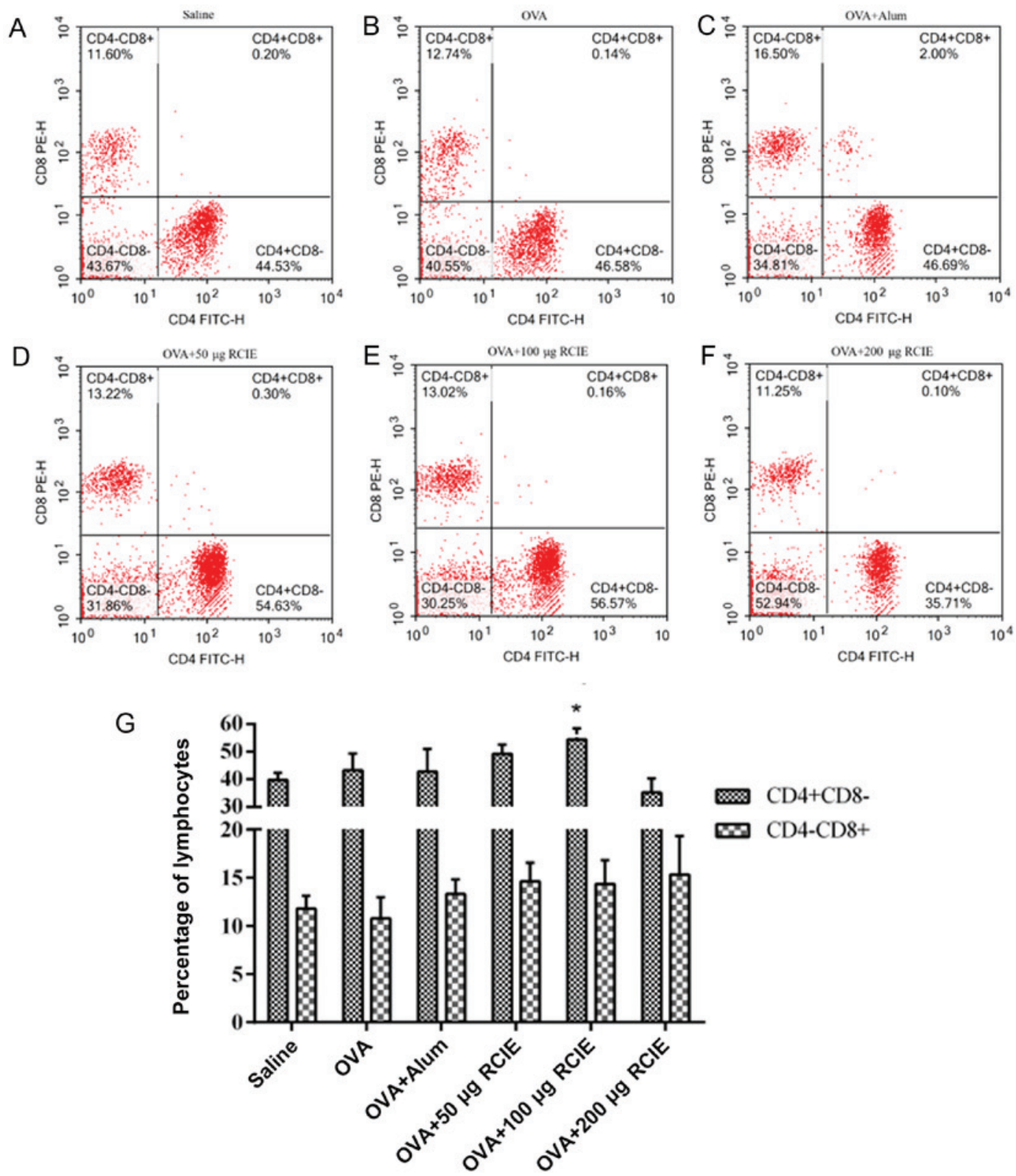

Figure 4. Effect of RCIE or alum adjuvant on $\mathrm{CD}^{+}{ }^{+}$and $\mathrm{CD} 8^{+} \mathrm{T}$ cell populations in the peripheral blood of OVA-immunized mice. Representative flow cytometry dot plots showing the population of $\mathrm{CD} 4^{+}$and $\mathrm{CD} 8^{+} \mathrm{T}$ cells in the peripheral blood from mice in the (A) Saline, (B) OVA, (C) OVA + alum, (D) OVA $+50 \mu \mathrm{g}$ RCIE, (E) OVA $+100 \mu \mathrm{g}$ RCIE and (F) OVA $+200 \mu \mathrm{g}$ RCIE groups. (G) Quantified flow cytometry data. Values are presented as mean \pm SEM (n=10). ${ }^{*} \mathrm{P}<0.05$ vs. OVA. OVA, ovalbumin; alum, aluminum hydroxide gel; RCIE, red clover isoflavone extract; PE, phycoerythrin.

OVA + RCIE $(50 \mu \mathrm{g})$ and OVA + alum groups. Additionally, the proportion of $\mathrm{CD} 8^{+} \mathrm{T}$ cells in the OVA-immunized mice was not significantly affected by RCIE.

Effect on cytokine mRNA levels in splenocytes. The levels of IL-2, IFN- $\gamma$, T-bet, IL-10, GATA-3 and IL-4 mRNA expression in ConA-stimulated mouse splenocytes are shown in Table II. Following ConA treatment, the mRNA expression levels of the Th2-associated cytokines IL-4, IL-10 and transcription factor GATA-3, as well as those of Th1-associated cytokines IL-2, IFN- $\gamma$ and transcription factor T-bet were significantly increased in splenocytes from the OVA + RCIE groups at certain concentrations compared with those in the OVA group $(\mathrm{P}<0.05$ or $\mathrm{P}<0.01)$. However, only IL-4, IL-10 and GATA-3 mRNA expression levels were observed to be significantly higher in the OVA + alum group compared with the OVA group $(\mathrm{P}<0.05$ or $\mathrm{P}<0.01)$. These results suggest that the inclusion of RCIE during immunization induced the gene expression of Th1/Th2 cytokines and transcription factors in splenocytes following stimulation with ConA.

RCIE promotes anti-infection effects in immunized mice. Three days following inoculation with $E$. coli vaccine, the mice were challenged with pathogenic porcine $E$. coli. In the vehicle group, the mice began to exhibit symptoms associated with infection $4 \mathrm{~h}$ following bacterial challenge including curling, diminished movement, increased depression, ruffled fur, shortness of breath and death within $6 \mathrm{~h}$, with no mice surviving beyond $24 \mathrm{~h}$. In the RCIE + E. coli group, deaths were observed commencing at $18 \mathrm{~h}$ following 
Table II. mRNA expression levels of cytokines and transcription factors in splenocytes isolated from OVA-immunized mice.

\begin{tabular}{lccccc}
\hline Gene & OVA & OVA + alum & OVA $+50 \mu \mathrm{g}$ RCIE & OVA + 100 $\mu \mathrm{g}$ RCIE & OVA + 200 $\mu \mathrm{g}$ RCIE \\
\hline IL-2 & $1.01 \pm 0.12$ & $1.27 \pm 0.34$ & $1.07 \pm 0.32$ & $1.99 \pm 0.39^{\mathrm{a}}$ & $1.65 \pm 0.29^{\mathrm{a}}$ \\
IFN- $\gamma$ & $1.01 \pm 0.13$ & $1.08 \pm 0.32$ & $2.25 \pm 0.37^{\mathrm{b}}$ & $2.32 \pm 0.39^{\mathrm{b}}$ & $1.63 \pm 0.63^{\mathrm{a}}$ \\
T-bet & $1.00 \pm 0.08$ & $1.19 \pm 0.12$ & $2.13 \pm 0.52^{\mathrm{a}}$ & $2.28 \pm 0.63^{\mathrm{a}}$ & $1.26 \pm 0.32$ \\
IL-4 & $1.02 \pm 0.22$ & $4.07 \pm 1.32^{\mathrm{b}}$ & $2.33 \pm 0.60^{\mathrm{a}}$ & $2.49 \pm 0.18^{\mathrm{a}}$ & $1.51 \pm 0.12$ \\
IL-10 & $1.01 \pm 0.17$ & $3.07 \pm 1.02^{\mathrm{a}}$ & $1.70 \pm 0.77$ & $4.93 \pm 1.49^{\mathrm{b}}$ & $4.53 \pm 1.88^{\mathrm{b}}$ \\
GATA-3 & $1.02 \pm 0.21$ & $5.32 \pm 1.16^{\mathrm{b}}$ & $1.24 \pm 0.44$ & $2.19 \pm 0.62^{\mathrm{a}}$ & $1.40 \pm 0.26$ \\
\hline
\end{tabular}

Values are presented as mean \pm SEM $(\mathrm{n}=10)$. ${ }^{\mathrm{a}} \mathrm{P}<0.05$ and ${ }^{\mathrm{b}} \mathrm{P}<0.01$ vs. OVA. IL, interleukin; IFN- $\gamma$, interferon- $\gamma ;$ TNF- $\alpha$; tumor necrosis factor- $\alpha$; alum, aluminum hydroxide gel; RCIE, red clover isoflavone extract; OVA, ovalbumin.

bacterial challenge with no additional deaths observed $24 \mathrm{~h}$ after challenge. Since statistical significance could already be observed in the mortality rates between the four experimental groups at $48 \mathrm{~h}$ after bacterial challenge, all experiments were terminated at $48 \mathrm{~h}$ post-challenge. The survival rates of immunized mice were found to be $80 \%(8 / 10)$ for the RCIE group, $60 \%(6 / 10)$ for the alum + E. coli group and $30 \%$ (3/10) for the saline $+E$. coli group (Fig. 5). Compared with the vehicle and saline $+E$. coli groups, the survival rate in the RCIE $+E$. coli group was significantly higher $(\mathrm{P}<0.05)$. These results suggest that RCIE can significantly enhance the efficacy of $E$. coli vaccine.

\section{Discussion}

An ideal adjuvant should exhibit the following characteristics: i) Promotion of humoral and cell-mediated immunity with no toxic side effects; ii) be able to be delivered to the body via different routes and with different antigens; iii) leave no long-term residue as well as maintain stability when delivered via the oral route $(25,26)$. Although a number of adjuvants have been applied in vaccines, a majority of the materials used only elicit humoral immunity or exert undesirable side effects, limiting their potential use in vaccines (27). In the present study, no adverse clinical responses, including immune stress, growth inhibition and adverse reactions, were observed when RCIE was applied as the adjuvant. In addition, it was found that RCIE acted as an adjuvant to enhance the cellular immune responses in OVA-immunized mice. Compared with the control group, the levels of IgG and IgG-subclass antibodies were significantly increased, whereas splenocyte viability and cytokine expression were also significantly enhanced in the OVA + RCIE groups.

The type of adjuvant determines the type of elicited immune response, which in turn has a significant effect on the immunoprotective properties of the vaccine (28). The Th1-type immune response, mainly mediated by Th1 helper cells, is associated with increased levels of IL-2, IFN- $\gamma$, IgG2a, IgG2b and IgG3. These immune responses are necessary for the activation of CTLs (24). By contrast, the Th2-type immune response is mainly associated with increased levels of IL-4, IL-5, IL-10, IgG1 and IgA (24). Currently, the most commonly used adjuvants, including water/oil emulsions and alum, only activate Th2-type responses (29). Although, other adjuvants such as

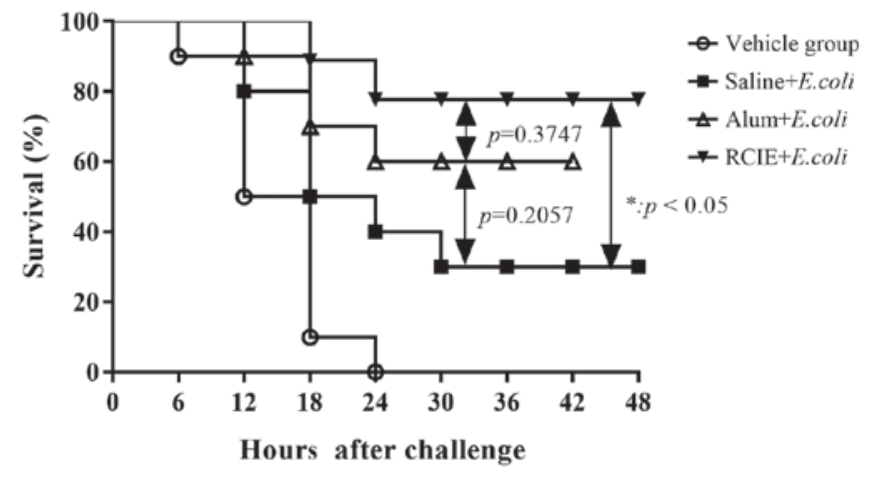

Figure 5. Effect of RCIE or alum adjuvant during immunization with inactivated $E$. Coli on the survival in mice challenged with pathogenic E. coli. Mice were challenged with pathogenic porcine $E$. coli 3 days following inoculation with the $E$. coli vaccine alone or in combination with alum or RCIE, following which survival was monitored for $48 \mathrm{~h}$. Alum, aluminum hydroxide gel; RCIE, red clover isoflavone extract.

liposomes and their derivatives have been found to give rise to Th-type responses characterized by the production of cytokines and IgG antibody subclasses, they are incapable of stimulating the production of CTLs against soluble or exogenous antigens (e.g., viral particles and soluble MHC molecules) (30).

To the best of our knowledge, there have not been any studies investigating the adjuvant activity of RCIE. In the present study, the effect of RCIE as an adjuvant for inducing Th1 or Th2 immune responses in OVA-immunized mice was evaluated. ConA and LPS are able to induce the proliferation of T cells and B cells, respectively (31). In the RCIE immunization groups in the present study, ConA and LPS were demonstrated to significantly enhance splenocyte viability in vitro. However, no significant differences were detected between the OVA and OVA + alum groups. Since the majority of spleen cells are lymphocytes (3), these results suggest that RCIE could significantly increase the activation potential of lymphocytes in OVA-immunized mice. IgG is the most abundant immunoglobulin isoform in serum, which can provide protection against most blood-borne diseases. IgG is divided into four subtypes: $\operatorname{IgG} 1, \operatorname{IgG} 2 \mathrm{a}, \operatorname{IgG} 2 \mathrm{~b}$ and $\operatorname{IgG} 3$, with their distribution regulated by the cytokine profile (32). The levels of IgG and IgG1 in the OVA-immunized mice were enhanced by 50 , 100 or $200 \mu \mathrm{g}$ RCIE compared with those in the OVA group. Although alum significantly enhanced the levels of IgG1 in the 
OVA-immunized mice, the levels of IgG2a remained unchanged compared with those in the mice immunized with OVA alone. As GATA-3 is a Th2 cytokine transcription factor (33), this may be related to the induction of the GATA-3 gene expression. Therefore, RCIE application may be effective in activating the Th1- and Th2-type immune response at appropriate levels, which is associated with increased levels of IgGl and IgG2a.

The possible effects of RCIE on the Th1/Th2 immune response were also examined by flow cytometry and ELISA. The proportion of $\mathrm{CD}^{+} \mathrm{T}$ cells in the blood of mice immunized with OVA + RCIE $(100 \mu \mathrm{g})$ was higher compared with that in the OVA group. In addition, the levels of IL-4 and IL-5 as well as the levels of IL-2, IFN- $\gamma$ and TNF- $\alpha$ were increased by RCIE in the OVA-immunized mice. These results suggest that RCIE elicited both Th1 and Th2 immune responses to OVA in mice. Subsequently, the mice were immunized with RCIE and $E$. coli vaccine, following which a lethal dose of pathogenic E. coli was given after 3 days. Pathogenic E. coli produces exotoxins that can cause diarrhea, bleeding and even death in animals (34). Compared with the vehicle group, in which all mice died following bacterial challenge, RCIE significantly improved the survival rate of mice, which may be associated with the induction of Th1- and Th2-type immune responses and the rapid promotion of antibody production.

To examine the mechanism of Th1/Th2 cytokines further, RT-qPCR was utilized to analyze the mRNA expression levels of IL-2, IFN- $\gamma$, IL-4 and IL-10, all of which were found to be enhanced by RCIE. The original decision of T cells to differentiate into Th1 or Th2 subtypes is regulated by transcription factors T-bet or GATA-3 (33). The present study found that the mRNA levels of T-bet and GATA-3 were increased in splenocytes isolated from the immunized mice in the RCIE group. These results suggest that RCIE has the potential to induce Th1 and Th2 immune responses.

There was a notable change in the type of Th1 or Th2 immune response that was induced with varying concentrations of RCIE, in agreement with other studies $(35,36)$. The type of immune response activated is dependent upon the type of infection involved. The Th1-type immune response can neutralize intracellular microorganisms, primarily via the involvement of IgG2a, IFN- $\gamma$, CTLs and IL-12, whereas the clearance of extracellular pathogens is dependent on the humoral immune response, primarily involving IgG1, IL-4, IL-5 and IL-10 (37). However, a key challenge in the field of vaccine adjuvants remains the activation of an aberrant immune response and disease deterioration induced by an adjuvant. The selection of the correct adjuvant may be an effective strategy for producing different types of immune responses. Indeed, CpG-DNA has been demonstrated to stimulate local susceptibility, causing potent CTL responses and Th1-polarized immune responses to subsequent infections or antigen challenge (38). Alum adjuvants are generally recognized as safe and effective stimulators of Th2 immunity, resulting in the production of high levels of IgG1 (39). Additionally, total ginseng saponins have been reported to potentiate natural killer cell activity, increase IFN production and stimulate the activity of CTLs and the Th1 immune response. In particular, Rivera et al reported that ginsenoside Rb1 stimulated higher antibody titers compared with alum adjuvant vaccines (40). It has also been reported that adjuvants such as oil/ginseng saponin or alum/Rg1 regulate
Th1 or Th2 immune responses (38). These previous reports emphasize the importance of the type of adjuvant applied to the immune activation that is induced.

Based on the present study, it may be concluded that the use of RCIE as an adjuvant increased specific antibody and cellular responses against OVA in mice by regulating the gene expression of Th1/Th2 cytokines and transcription factors. In addition, the subsequent potentiation of both Th1 and Th2 immune responses by RCIE significantly improved the efficacy of the E. coli vaccine.

\section{Acknowledgements}

The authors would like to thank Dr Jingxun Ni (Longyan University, Longyan, Fujian, P.R. China) for kindly providing the Pathogenic porcine Escherichia coli.

\section{Funding}

This work was supported by the Fujian Science and Technology Plan Guiding Project of China (grant no. 2015N0029), the Longyan Qimai Science and Technology Innovation Fund (grant no. 2018LYQM0201) and special projects for local science and technology development guided by the central government (grant no. 2019L3011).

\section{Availability of data and materials}

The datasets used and/or analyzed in the current study are available from the corresponding author on reasonable request.

\section{Authors' contributions}

$\mathrm{HC}$ and LQ designed the experiments. HC performed the experiments. HC, XZ, MC and LL collected the data. HC and ZG analyzed the data. HC prepared the manuscript and LQ revised the manuscript. All authors read and approved the final manuscript.

\section{Ethics approval and consent to participate}

All experiments were performed in accordance with the guidelines of the Animal Ethics Committee of Fujian province (Fujian, China) and were approved by the Institutional Animal Care and Use Committee of Longyan University (Fujian, China).

\section{Patient consent for publication}

Not applicable.

\section{Competing interests}

The authors declare that they have no competing interests.

\section{References}

1. Martins KAO, Cooper CL, Stronsky SM, Norris SLW, Kwilas SA, Steffens JT, Benko JG, van Tongeren SA and Bavari S: Adjuvant-enhanced CD4 T Cell responses are critical to durable vaccine immunity. EbioMedicine 3: 67-78, 2016. 
2. Tandrup Schmidt S, Foged C, Korsholm KS, Rades T and Christensen D: Liposome-based adjuvants for subunit vaccines: Formulation strategies for subunit antigens and immunostimulators. Pharmaceutics 8: E7, 2016.

3. Sun HX, Ye YP, Pan HJ and Pan YJ: Adjuvant effect of panax notoginseng saponins on the immune responses to ovalbumin in mice. Vaccine 29: 3882-3889, 2004.

4. Jiang W, Zhu T, Wang YX, Zhang ZX and Shan JJ: Application of polysaccharide adjuvants in vaccines. Chin J N Drugs 21: 1470-1478, 2012

5. Xie Y, Pan H, Sun H and Li D: A promising balanced Th1 and Th2 directing immunological adjuvant, saponins from the root of platycodon grandiflorum. Vaccine 26: 3937-3945, 2008

6. Eshaghkhani Y, Sanati MH, Nakhjavani M, Safari R, Khajavi A Ataei M and Jadali Z: Disturbed Th1 and Th2 balance in patients with graves' disease. Minerva Endocrinologica 1: 28-36, 2016.

7. Hussein MM and Ahmed MM: The Th1/Th2 paradigm in lambda cyhalothrin-induced spleen toxicity: The role of thymoquinone. Environ Toxicol Pharmacol 41: 14-21, 2016.

8. Haghshenas MR, Khademi B, Ashraf MJ, Ghaderi A and Erfani N: Helper and cytotoxic T-cell subsets (Th1, Th2, Tc1, and $\mathrm{Tc} 2)$ in benign and malignant salivary gland tumors. Oral Dis 22: 566-572, 2016

9. Germann T, Bongartz M, Dlugonska H, Hess H, Schmitt E, Kolbe L, Kölsch E, Podlaski FJ, Gately MK and Rüde E: Interleukin-12 profoundly up-regulates the synthesis of antigen-specific complement-fixing IgG2a, IgG2b and IgG3 antibody subclasses in vivo. Eur J Immunol 25: 823-829, 1995.

10. Rostamian M, Sohrabi S, Kavosifard H and Niknam HM: Lower levels of IgG1 in comparison with IgG2a are associated with protective immunity against Leishmania tropica infection in BALB/c mice. J Microbiol Immunol Infect 50: 160-166, 2017.

11. Mochizuki S, Morishita H, Kobiyama K, Aoshi T, Ishii KJ and Sakurai K: Immunization with antigenic peptides complexed with $\beta$-glucan induces potent cytotoxic T-lymphocyte activity in combination with CpG-ODNs. J Control Release 220: 495-502, 2015.

12. Liu L, Yu C, Wang C, Shao M, Yan Z, Jiang X, Chi S, Wang Z, Wei $\mathrm{K}$ and Zhu R: Immuno-enhancement of taishan pinus massoniana pollen polysaccharides on recombinant Bordetella avium ompA expressed in pichia pastoris. Microb Pathog 95: 54-61, 2016.

13. Song X and Hu S: Adjuvant activities of saponins from traditional Chinese medicinal herbs. Vaccine 27: 4883-4890, 2009.

14. Zhu YJ, Tian SY, Zhang Y, Ren HL and Bing LI: Effect of red clover isoflavones on immune function and antioxidant activity in broilers. J Shenyang Agricultural University 39: 699-703, 2008.

15. Rasouli E and Jahanian R: Improved performance and immunological responses as the result of dietary genistein supplementation of broiler chicks. Animal 9: 1473-1480, 2015.

16. Huang BP, Liu YB and Liu YH: Effects of astragalus polysaccharides on production performance of weanling piglets and immune effect of classical swine fever vaccine. J Anhui Agricultural Sci 17: 5493-5496, 2014.

17. Cao P, Jeyabalan J, Aqil F, Ravoori S, Gupta RC and Vadhanam MV: Polymeric implants for the delivery of green tea polyphenols. J Pharm Sci 103: 945-951, 2014.

18. Ryanborchers TA, Park JS, Chew BP, Mcguire MK, Fournier LR and Beerman KA: Soy isoflavones modulate immune function in healthy postmenopausal women. Am J Clin Nutr 83: 1118-1125, 2006.

19. Ni J, Huang H, Chen T, Shen J and Lin W: Improved early humoral immune response to antigens by Protamine protein. Chin J Prev Veterinary Med 4: 342-346, 2018.

20. Chen HQ and Jin ZY: Study on extraction technology of trifolium pratense isoflavones. Food Sci 26: 156-159, 2005.

21. Feng YL, Yuan YM and Xia Y: Hydrolysis of soybean isoflavone by alkali. China Oils Fats 34: 56-58, 2009.

22. Yang ZG, Sun HX and Fang WH: Haemolytic activities and adjuvant effect of Astragalus membranaceus saponins (AMS) on the immune responses to ovalbumin in mice. Vaccine 44: 5196-5203, 2005.
23. Cao ZM, Wang MZ, Wang L, Zhang JY, Wang HR, Li JX and Wang XZ: Establishment and evaluation of mouse model of ulcerative colitis. China Animal Husbandry Veterinary Med 1: 171-175, 2016

24. Ni J, Bi S, Xu W, Zhang C, Lu Y, Zhai L and Hu S: Improved immune response to an attenuated pseudorabies virus vaccine by ginseng stem-leaf saponins (GSLS) in combination with thimerosal (TS). Antiviral Res 132: 92-98, 2016.

25. Aucouturier J, Dupuis L and Ganne V: Adjuvants designed for veterinary and human vaccines. Vaccine 19: 2666-2672, 2001.

26. O'Hagan DT, Mackichan ML and Singh M: Recent developments in adjuvants for vaccines against infectious diseases. Biomol Eng 18: 69-85, 2001.

27. Hunter RL: Overview of vaccine adjuvants: Present and future. Vaccine 3(Suppl 20): S7-S12, 2002.

28. Longhi MP, Trumpfheller C, Idoyaga J, Caskey M, Matos I, Kluger C, Salazar AM, Colonna M and Steinman RM: Dendritic cells require a systemic type I interferon response to mature and induce CD4+ Th1 immunity with poly IC as adjuvant. J Exp Med 206: 1589-1602, 2009

29. Xie Y, Sun HX and Li D: Platycodin D is a potent adjuvant of specific cellular and humoral immune responses against recombinant hepatitis B antigen. Vaccine 27: 757-764, 2009

30. Zhao W, Gang YU, Hao PL, Han XX, Huang XY and Yang XM: Effect from cationic liposomes DOTAP as adjuvant on H5N1 influenza split vaccine. Prog Microbiol Immunol 44: 1-9, 2016.

31. Huong PT, Lee CH, Li MH, Lee MY, Kim JK, Lee SM, Seon JH, Lee DC and Jeon YJ: Characterization and immunopotentiating effects of the glycoprotein isolated from dioscorea batatas. Korean J Physiol Pharmacol 15: 101-106, 2011.

32. Adame-Gallegos JR, Shi J, Mcintosh RS and Pleass RJ: The generation and evaluation of two panels of epitope-matched mouse IgG1, IgG2a, IgG2b and IgG3 antibodies specific for plasmodium falciparum and Plasmodium yoelii merozoite surface protein 1-19 (MSP1(19)). Exp Parasitol 130: 384-393, 2012.

33. Chakir H, Wang H, Lefebvre DE, Webb J and Scott FW: T-bet/GATA-3 ratio as a measure of the Th1/Th2 cytokine profile in mixed cell populations: Predominant role of GATA-3. J Immunol Methods 278: 157-169, 2003.

34. Watson VE, Jacob ME, Flowers JR, Strong SJ, Debroy C and Gookin JL: Association of atypical enteropathogenic Escherichia coli with diarrhea and related mortality in kittens. J Clin Microbiol 9: 2719-2735, 2017.

35. Sun $\mathrm{H}, \mathrm{He} \mathrm{S}$ and Shi M: Adjuvant-active fraction from Albizia julibrissin saponins improves immune responses by inducing cytokine and chemokine at the site of injection. Int Immunopharmacol 22: 346-355, 2014.

36. Ouyang K, Chen L, Sun H, Du J and Shi M: Screening and appraisal for immunological adjuvant-active fractions from platycodon grandiflorum total saponins. Immunopharmacol Immunotoxicol 34: 126-134, 2012.

37. Yang Z, Chen A, Sun H, Ye Y and Fang W: Ginsenoside Rd elicits Th1 and Th2 immune responses to ovalbumin in mice. Vaccine 25: 161-169, 2007.

38. Marinaro M, Fasano A and De Magistris MT: Zonula occludens toxin acts as an adjuvant through different mucosal routes and induces protective immune responses. Infect Immun 71: 1897-1902, 2003.

39. Jafari M, Moghaddam Pour M, Taghizadeh M, Masoudi S and Bayat Z: Comparative assessment of humoral immune responses of aluminum hydroxide and oil-emulsion adjuvants in influenza (H9N2) and Newcastle inactive vaccines to chickens. Artif Cells Nanomed Biotechnol 45: 84-89, 2017.

40. Rivera $\mathrm{E}, \mathrm{Hu} \mathrm{S}$ and Concha $\mathrm{C}$ : Ginseng and aluminium hydroxide act synergistically as vaccine adjuvants. Vaccine $21: 1149-1157$, 2003.

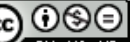

This work is licensed under a Creative Commons Attribution-NonCommercial-NoDerivatives 4.0 International (CC BY-NC-ND 4.0) License. 